\title{
Editorial 2021: Changes to the guidelines for authors for publishing in Archives of Virology
}

\author{
Tim Skern ${ }^{1}$
}

Received: 22 December 2021 / Accepted: 24 December 2021 / Published online: 29 January 2022

(c) The Author(s), under exclusive licence to Springer-Verlag GmbH Austria, part of Springer Nature 2021

2021 ends in the same way as it started, dominated by the evolution and pathogenicity of SARS-CoV-2. The world is currently holding its breath to observe how virulent the omicron variant will be and whether this variant will overcome the protection provided by the current vaccines developed against viruses originating from the beginning of the pandemic. Over 150 submissions with SARS-CoV-2 in the title were received by Archives of Virology in 2021, reflecting the effect of SARS-CoV-2 on our world. The most important of the 50 or so of these submissions that were published can be easily found in the journal collection "Important coronavirus papers in 2021 in Archives of Virology". Papers published in 2021 will added until the end of the year.

Changes in the "Instructions for Authors"

During 2021, three important issues came to light that necessitated changes to the "Instructions to Authors".

\section{Listing of author contributions}

The first concerns the listing of author contributions. Prior to and during 2021, it was optional for authors to provide a listing of the contributions of each author to a submission. In 2021, there were disputes arising in a small number of submissions about the contributions of authors. In order to eliminate or at least reduce the possibility of such disputes, we have now made it mandatory for the corresponding author to provide a list of author contributions when submitting to Archives of Virology. Submissions without such a list will be returned directly to the authors.

Changes in "Annotated Sequence Records" for bacteriophages

From 2022, it will no longer be possible to submit an annotated sequence record for bacteriophages that have been isolated. In order to publish this information, transmission electron micrographs, growth curves and/or host range investigations must be carried out. Such submissions will thus qualify as brief reports or original articles, depending on their content

\section{New section on data from clinical trials}

Given the importance of reliable clinical trial data, we have decided that submissions on clinical trials to Archives of Virology must also provide the raw data from the trial. Authors are recommended to read the following article in order to suitably prepare their manuscript for peer review [1]. Notably, this article illustrates that clinical trials with 100 or fewer participants are unlikely to provide useful information.

Finally, I would like to thank all the reviewers, two whistle-blowers, the advisory board members, my fellow editors and the team at SpringerNature for their efforts in these unusual times. Without your support and expertise, it would not be possible to produce the journal in the quality that scientific journals should show.

\section{Reference}

1. Pearson H (2021) How COVID broke the evidence pipeline. Nature 593:182-185. https://doi.org/10.1038/d41586-021-01246-X

Publisher's Note Springer Nature remains neutral with regard to jurisdictional claims in published maps and institutional affiliations.
Tim Skern

timothy.skern@muv.ac.at

1 Medical University of Vienna, Vienna, Austria 